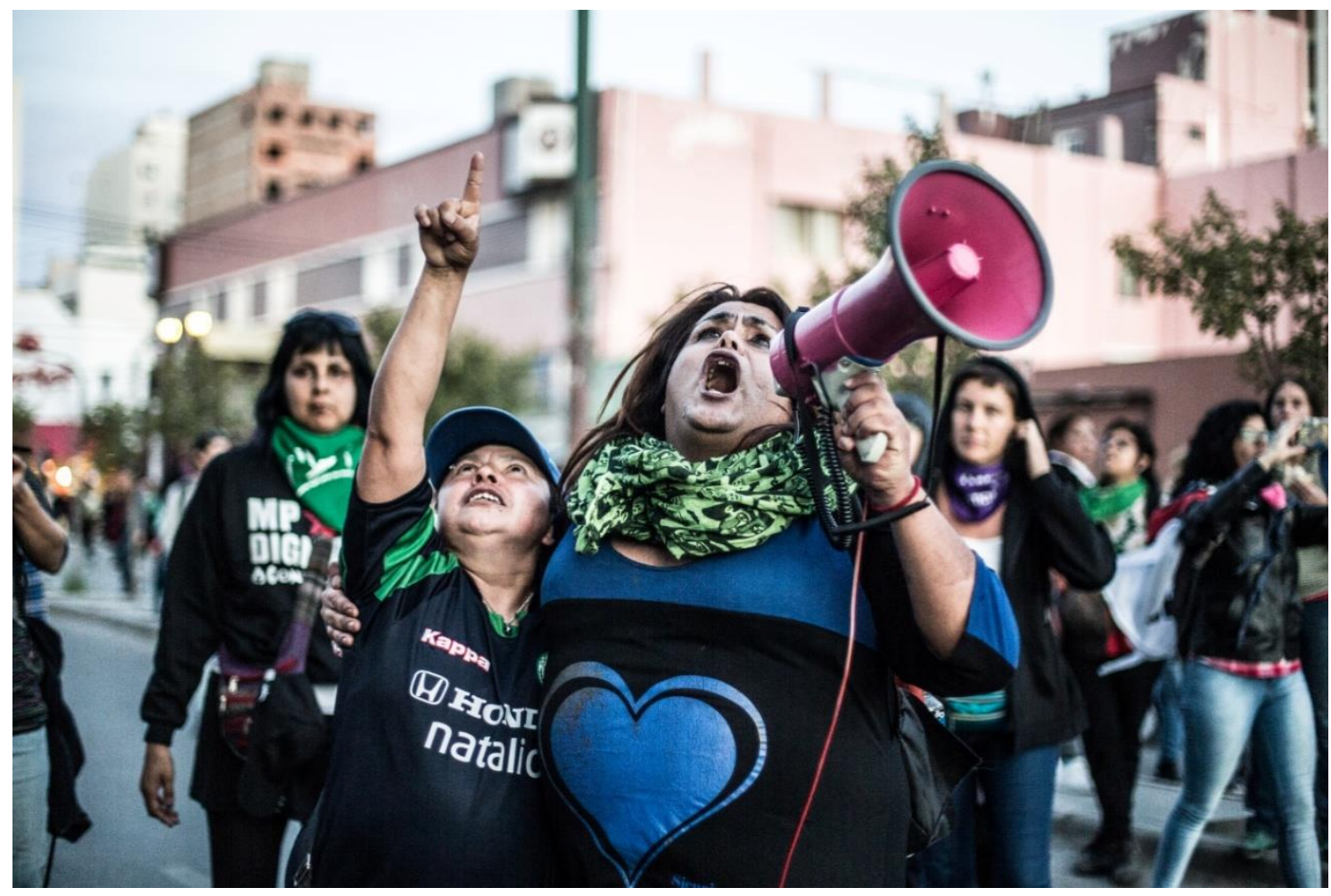

FOTOS: Irina Morán - Revista Alfilo - Periodista Feminista. Militante de Ni Una Menos Córdoba y Mujeres por un parto Respetado 


\title{
REVISITANDO UNA GIORNATA PARTICOLARE: FEMINISMO, GÊNERO E SOCIOLOGIA DA EDUCAÇÃO EM DISPUTA
}

\author{
Daniela Auad ${ }^{1}$
}

\begin{abstract}
Resumo: Ao evocar momento histórico e acontecimentos passados para analisar inquietações que são foco de nossas preocupações presentes, como postula Peter Burke, em História como alegoria (1995), o presente artigo noticia, ineditamente, observações de campo de pesquisa sobre relações de gênero nos cursos de Pedagogia, em que se encontram ainda desafios e obstáculos de um percurso inacabado. Esta pesquisa tem analisado disciplinas que abordam as questões de gênero em cursos de Pedagogia de Universidades Federais do Sudeste do Brasil. A partir desta pesquisa e em análise de específicos episódios de campo, percebidos como desdobramento do Golpe de Estado, sob o qual estamos vivendo, o texto aborda o fomento de ódios, tentativas de apagamento de Direitos e a potencialização de disputas que colocam em foco tanto a disciplina Sociologia da Educação quanto as maneiras de abordar as relações de gênero em cursos de Formação Docente na Educação Superior, os quais graduam profissionais para atuarem na Educação Básica.
\end{abstract}

Palavras-chave: Sociologia da Educação; Relações de Gênero; Educação Superior; Formação docente; Golpe de Estado.

\section{REVISITACIÓN UNA GIORNATA PARTICOLARE: FEMINISMO, GÉNERO Y SOCIOLOGÍA DE LA EDUCACIÓN EN DISPUTA}

Resumen: Al evocar momento histórico y acontecimientos pasados para analizar inquietudes que son foco de nuestras preocupaciones presentes, como postula Peter Burke, en Historia como alegoría (1995), el presente artículo informa ineditamente observaciones de campo de la investigación sobre relaciones de género en los cursos de Pedagogía, donde se encuentran aún desafíos y obstáculos de un recorrido inacabado. Esta investigación ha analizado disciplinas que abordan las cuestiones de género en cursos de Pedagogía de Universidades Federales del Sudeste de Brasil. A partir de esa investigación y en análisis de determinados episodios de campo percibidos como desdoblamiento del Golpe de Estado bajo el cual estamos viviendo, el texto aborda fomento de odios, intento de borrado de Derechos y potenciación de disputas que ponen en foco tanto la asignatura Sociología de la política Educación como maneras de abordar las relaciones de género en cursos de Formación Docente en la Educación Superior, los cuales graduan profesionales para actuar en la Educación Básica.

Palabras clave: Sociología de la Educación; Relaciones de género; Educación universitaria; Formación docente; Golpe de Estado.

\section{INTRODUÇÃO}

No presente artigo, é tecida a escrita que, ao acionar a História como alegoria, chama à memória momentos históricos e acontecimentos passados, com o objetivo de analisar inquietações e descaminhos - pontos para os quais convergem nossas preocupações presentes. Dessa maneira, são descritas e investigadas, ineditamente, observações de campo de pesquisa sobre relações de gênero nos cursos de Pedagogia, nos quais se encontram ainda desafios e obstáculos de um percurso inacabado no

1 Graduação, mestrado e doutorado pela Universidade de São Paulo. Professora do Programa de Pós-graduação em Educação da Universidade Federal de Juiz de Fora - UFJF. 
tocante à categoria que advém do movimento feminista e foi, de maneira potente e transformadora, apropriada por outros movimentos sociais e setores variados dos estudos acadêmicos. A pesquisa sobre o percurso inacabado da categoria gênero nos Cursos de Pedagogia, da qual se beneficia a escrita delineada no texto, examina disciplinas que abordam as questões de gênero em cursos de Pedagogia de Universidades Federais do Sudeste do Brasil. A partir dessa pesquisa e em análise de específicos episódios de campo, percebidos como desdobramentos do Golpe de Estado vivido no Brasil no ano de 2016, o texto aborda o fomento de ódios, tentativas de apagamento de Direitos e a potencialização de disputas que colocam em foco tanto a disciplina Sociologia da Educação quanto maneiras de abordar as relações de gênero em cursos de Formação Docente na Educação Superior.

No âmbito da abordagem assumida, inicialmente, há de se destacar que, ainda que não possamos entender o presente, banalizando-o como se fosse um replay ou uma mera reconstituição do passado, é possível encontrar relações entre eventos ao observar acontecimentos históricos que resultaram no Fascismo. Tal fenômeno foi muito bem descrito como singular exemplo modelar, no filme Una giornata particolare dirigido por Ettore Scola em 1977, ou no fenômeno denominado Macarthismo, ou ainda em campo de pesquisa em contexto do Golpe de Estado no Brasil, na atualidade, como será descrito doravante. A relação entre esses eventos, por mais que tenham suas singularidades, pode se referir ao anúncio de scripts históricos que podem ir se deslindando no transcorrer dos acontecimentos, conforme vão se enfileirando elementos presentes e marcantes em todos eles, se reapresentando de modo encadeado, de maneira a colocá-los em bases de comparação e no interior de análises assemelhadas. Assim, o caminho analítico, aqui proposto, passa pelo exame de distanciamentos e proximidades no tocante à repetição de imagens, figuras, ideias e qualidades como elementos que tentam fantasiar ou disfarçar autoritarismo, preconceito, xenofobia, misoginia, intolerância religiosa, sendo essas representações encontradas em variados momentos históricos e na atualidade de docentes de Ensino Superior no Brasil.

Assim, mais do que colocar o presente como uma repetição do passado, o que aqui se ensaia é a busca por elementos, vivências, rituais e caminhos que nos sirvam de pistas para assegurar a volta da democracia plena, já que, no Brasil, vem se ensaiando, também, o retrocesso ditatorial. Nesse sentido, ao evocar momento histórico e acontecimentos passados para analisar inquietações que são foco de nossas preocupações presentes, como postula Peter Burke, em História como alegoria, o 
presente artigo se debruça sobre específico episódio de campo percebido como desdobramento do Golpe de Estado, sob o qual estamos vivendo desde que a Presidenta Dilma Rousseff foi retirada do cargo para o qual foi eleita sem ter cometido crime algum. (BURKE, 1995) O texto aborda o fomento de ódios, tentativas de apagamento de Direitos e a potencialização de disputas que colocam em foco tanto a disciplina Sociologia da Educação quanto maneiras de abordar as relações de gênero em cursos de Formação Docente na Educação Superior, os quais graduam profissionais para atuarem na Educação Básica.

Em outras palavras, trata-se de dizer que, a partir de ataques às instituições constituídas, de momentos e movimentos de privação de cidadania, forma-se um caldo de insegurança jurídica e política capaz de fazer brotar fascismos no interior das variadas disputas de campo, seja no âmbito da História da Itália, recuperada como potente alegoria no filme citado desde o título; seja na perspectiva da perseguição americana contra aqueles e aquelas que seriam vistos como comunistas, durante o Marcathismo; seja na seara de disciplinas de graduação que consideram gênero, raça e orientação sexual como possíveis categorias de análise, dentre outras.

Em um país cuja jovem democracia está sob forte ataque continuamente, haja vista os altos índices de extermínio da juventude negra, o caos gerado pelo golpe inicialmente parlamentar, com o qual Dilma Rousseff foi retirada do cargo máximo do Executivo, para o qual foi eleita, ofende o sistema de respeito, de legalidade e de legitimidade sobre o qual o social transita com valores republicanos e democráticos. Incautas intromissões jurídicas em todo o País, nas mais diversas searas, tornam leis instrumentos disponíveis para manobras que sequestram a Constituição de 1988 e colocam sob suspeita e interdição as categorias sob as quais temos desenvolvido pesquisa, docência e extensão; a partir das quais temos construído nossa participação política, assim como nossas militâncias e ativismos; com as quais temos debatido nossas identidades e angariado, nas políticas públicas e na vida cotidiana, reconhecimento e redistribuição (FRASER, 2006).

Com a consideração dessa conjuntura, o texto analisa episódios coletados em pesquisa de campo, que tem como objeto disciplinas dos cursos de Pedagogia que consideram, nos seus debates, feminismo e relações de gênero, em Universidades Federais no Sudeste. Trata-se de pesquisa que analisa, ainda que como percurso inacabado mas em andamento, a consideração de gênero como categoria e como tema a ser debatido na formação em nível de graduação. Cumpre destacar que a pesquisa é rica 
em resultados e tem como fontes ementas, entrevistas docentes e discentes, e-mails trocados com coordenações de curso e chefias de departamento, bem como análise documental e bibliográfica. $\mathrm{O}$ trabalho tem se encaminhado para conclusões que tem sido tematizadas em um conjunto de artigos, como o que se apresenta em tela.

A fim de explorar situações do campo da pesquisa citada, doravante traremos situação de campo e sua posterior análise, a partir de breve histórico e caracterização de sujeito de pesquisa, docente da disciplina Sociologia da Educação, em Universidade Federal da região Sudeste. Há de se ressaltar que a docente em questão, assim como a Universidade e demais pessoas envolvidas nessa narrativa, não terão seus nomes aqui divulgados a bem do anonimato e, sobretudo, porque, no atual estado dos acontecimentos vividos, o que ali se passou pode ocorrer - e geralmente ocorre de diferentes ou até iguais maneiras - em muitas outras instituições e com outras pessoas participantes de situações semelhantes, infelizmente. Cumpre ainda destacar que a autora do presente artigo, pesquisadora das situações analisadas, poderia estar no lugar da docente a quem se dá voz no presente artigo. Da mesma maneira, pessoas leitoras deste texto também poderiam estar no lugar do sujeito de pesquisa aqui focalizado. Assim, mais do que nomear pessoas ou instituições nestes escritos, almeja-se mostrar que o pessoal e particular é produzido pelo contexto político e de crise da "coisa pública", esta entendida não apenas como os espaços e instituições públicas, mas, sobretudo, a República e os valores republicanos.

Desse modo, a possibilidade de repetição do que será descrito e analisado no presente artigo nos mostra que "cada caso não é um caso", como relembra a antropóloga Cláudia Fonseca. (FONSECA,1999). Essa possibilidade de partir do particular para o geral e de suscitar novos estudos a partir do que aqui se noticia se dá, especialmente, em razão do borbulhante caldo de desrespeito das básicas noções democráticas com as quais temos convivido. Esse ambiente criado pelo ressuscitar e arrefecer de tendências de ódio e de discriminação contra aquilo que é percebido como o "diferente" conta não apenas com dados de pesquisa, mas é endossado pela aproximação desses dados com alegorias históricas, fílmicas, textuais e midiáticas que utilizaremos no âmbito da análise.

\section{O PRESENTE COMO REEDIÇÃO DO PASSADO AUTORITÁRIO}

A docente de Sociologia da Educação, como chamaremos a professora central para a situação de campo em tela, ao ter ingressado na carreira docente como servidora 
federal em 2006, em um Estado do Sudeste, em 2010, pediu redistribuição por razões pessoais e se mudou de cidade, de Universidade e de Estado, ainda que tenha permanecido na mesma região do País. A profissional que atuava há onze anos como docente em Instituição Federal já lecionava em um total de 21 anos na área de Sociologia da Educação, em universidades particulares e públicas, assim como no Ensino Médio, sempre com disciplinas da área de Sociologia.

Com intensa atividade de pesquisa comprovada no Currículo Lattes, a docente de Sociologia da Educação, pedagoga e doutora em Sociologia da Educação, auto se denomina feminista, como também é reconhecida por setores desse movimento social e em diversos meios. Autora de livros na área de Gênero e Educação e com trajetória fundamentada no campo dos Estudos de Gênero, a referida professora, com formação em graduação e pós pela Universidade de São Paulo, lecionou e leciona a disciplina que se encontra na área de Fundamentos da Educação para os primeiros períodos do curso de um Pedagogia, assim como eletivas para Pedagogia e Licenciaturas. Nas disciplinas sob sua responsabilidade, além de contemplar as abordagens de Pierre Bourdieu e Bernard Lahire, a docente focaliza a esperada tríade de clássicos formada por Marx, Weber e Durkheim, constantes em ementário e cotidiano das aulas. Ao lado disso, a docente construiu curso que, desde o ementário, aborda o caráter de intersseccionalidade das categorias Crenshaw (2002) na análise dos processos socializadores, na produção das desigualdades educacionais e no fazer, tanto dos movimentos sociais quanto das políticas públicas. Assim, as disciplinas por ela lecionadas eram compostas pelo debate sobre a demandada, legítima e reconhecida categoria classe sempre em combinação intersseccional às categorias que, consideradas em alquimia Castro (1992), são primordiais para o entendimento dos processos socializadores e das relações entre Educação e Democracia.

Ao compor suas aulas, a docente parecia formular suas ementas e suas práticas com o que é aguardado usualmente para as disciplinas, somando a esses elementos textos sobre socialização e a categoria raça Cavaleiro (2003), socialização e a categoria gênero Louro (2012), socialização e a categoria geração Mollo-Bouvier (2005), assim como o debate sobre intolerância religiosa e o extermínio da juventude negra expostos em matérias de jornal. Lecionando Sociologia da Educação desde que chegou há 7 anos naquela Faculdade de Educação, na qual foi encontrada para compor a pesquisa sobre o percurso inacabado do debate de gênero nos cursos de Pedagogia, a docente tinha fundado Grupo de Pesquisa cuja temática Educação e Comunicação deu origem a um 
Coletivo Feminista. Nesse contexto, a docente de Sociologia da Educação realizava ações de pesquisa, docência, extensão e administração voltadas para a afirmação a partir dos Feminismos Negro, Lésbico e em perspectiva interseccional, da mesma maneira como abordava a alquimia das categorias classe, raça, gênero e geração em sua sala de aula, nas disciplinas obrigatória, eletiva e optativa que lecionava na graduação e pós-graduação.

A breve caracterização acima expressa docente, não apenas adequada aos moldes de produtividade em pesquisa, docência e extensão, mas também engajada e com trabalho reconhecido tanto na esfera local da Administração Superior da Universidade quanto nas searas mais amplas da militância feminista e no âmbito da produção de conhecimento nas áreas de Educação. Pois, estando no desempenho de suas funções, a referida docente de Sociologia da Educação foi golpeada exatamente um ano após o brusco e antidemocrático ato que retirou de seu cargo a mulher eleita para presidir o Brasil.

Exatamente um ano após 31 de agosto de 2016 - dia em que os votos majoritários da população brasileira lhes foram negados e Dilma Rousseff foi deposta do cargo máximo do Executivo do Estado brasileiro -, a docente que lecionava Sociologia da Educação em um curso de Pedagogia em Universidade Federal da região Sudeste foi procurada por colega que trazia uma consulta, sob a forma de comentários e perguntas. A consulta era organizada e enviada, especialmente, por colegas que lecionavam na área de Metodologia de Ensino e trabalhavam, também, com inclusão e diversidade, no âmbito do que se configura como Educação Especial, na ampla área de Educação.

O colega docente narrou ter sido enviado por outras professoras que disseram estar preocupadas com conteúdos básicos de Sociologia da Educação. Estes, especialmente segundo as docentes responsáveis por disciplinas de metodologia de ensino destinadas às licenciaturas, não estariam sendo garantidos pela docente de Sociologia da Educação, em aulas da área de Fundamentos, em disciplina destinada ao curso de Pedagogia. Segundo o colega portador da consulta à docente de Sociologia de Educação, doravante chamado de Pombo Correio, o receio das docentes, doravante chamadas de Docentes Pela Neutralidade, se baseava em reclamações que elas teriam ouvido e acolhido de alunas, individualmente e de modo informal. Tais reclamações que elas enviaram, sob a forma de preocupações que passaram então a ser delas mesmas, davam conta de uma eventual lacuna quanto às abordagens clássicas, o que 
teria gerado receios quanto a uma formação que estivesse mais centrada em um olhar que seria "obcecado pelo gênero". Esse olhar - sabidamente fruto da trajetória, carreira e características da docente de Sociologia da Educação - estaria, na "opinião" das Docentes Pela Neutralidade, “colonizando a disciplina". O uso das aspas e do itálico se presta a trazer o relato feito pelo Pombo Correio à docente de Sociologia da Educação, com as impressões e termos das Docentes Pela Neutralidade. E, aqui, utilizo o grifo nos nomes adotados para os sujeitos envolvidos no emblemático episódio, pois cumpre a função de destacar os personagens da vida real, que logo encontrarão semelhança na alegoria fílmica que traremos, assim como encontram semelhanças com outros sujeitos em outros momentos históricos da História do Brasil e de outros países nos quais se vivenciou perseguição política de cunho antidemocrático.

Ao lado dessas percepções informais sobre o curso lecionado pela docente de Sociologia da Educação, aparentemente advindas de quem não realizou qualquer processo coletivo e democrático para proceder à avaliação docente e disciplinar sobre os conteúdos ensinados, seguia consulta trazida pelo Pombo Correio, com o seguinte teor: uma vez que a abordagem de gênero presente nas aulas de Sociologia da Educação preocupava algumas docentes e, segundo estas, preocupavam-se, também, algumas alunas, cumpriria que a docente de Sociologia deixasse a disciplina pela qual é responsável no escopo de suas funções a cargo de outras professoras, que, pretensamente, ensinariam sem adotar a categoria gênero, livrando a disciplina de possíveis contaminações e críticas. Assim, docentes de outras áreas e que prestaram outros concursos poderiam, segundo as Docentes Pela Neutralidade, se encarregar de lecionar a disciplina Sociologia da Educação em sistema de rodízio. Segundo a ideia proposta pelas Docentes Pela Neutralidade, isso garantiria o que seria o ensino dos clássicos de modo “neutro”. Diante do uso do termo neutro, nessa situação específica de pesquisa, é impossível para quem está em coleta e análise de dados não lembrar que se desejam neutras, no campo da política e da educação, as forças que estão a serviço de quem ocupa os lugares privilegiados e, a saber, fazem parte de grupos conhecidos como dominantes ou hegemônicos, em razão de serem identificados do lado oposto das minorias sociais e das forças que lutam pelo término das desigualdades.

A consulta contida na abordagem feita pelo docente denominado Pombo Correio à docente de Sociologia da Educação mais do que recado entre colegas e mais do que uma fofoca de corredor, nos tempos em que vivemos, foi sentida, lida e avaliada pela docente de Sociologia da Educação e por quem a escuta como sujeito de pesquisa, 
como um golpe fruto do Golpe de Estado que estamos vivendo no Brasil. No interior do Golpe, são gestados novos golpes cotidianos, de modo que se faça parecer banal que sejam retiradas dos lugares que legitimamente ocupam por direito tanto mulheres eleitas quanto mulheres publicamente concursadas. Retiram-nas - ou tentam as retirar - ao sabor de cortinas de fumaça repletas de parciais avaliações, manobras marcadas por equivocadas e imprecisas afirmações, bem como conservadoras e antidemocráticas ações, estas na direção de práticas que sequestram direitos adquiridos, seja por 54 milhões de votos, seja por legítimo concurso público de provas e títulos.

Ao ouvir as ponderações do colega Pombo Correio, a denominada docente de Sociologia da Educação narra ter dialogado com ele e, na sequencia, enviado ofício endereçado à Chefia de Departamento, Coordenação de Curso e Direção daquela Unidade de Ensino. A tentativa da docente era, segundo seu depoimento, trazer o debate para o campo da legitimidade e do funcionamento institucional transparente, de modo a retirar o discurso da sombra temerária das práticas distantes das decisões colegiadas e públicas, que podem ser tomadas por quem não de direito.

A docente de Sociologia da Educação ponderava, em ofício enviado e em conversa com colegas, um conjunto de fatos que delineavam tanto a importância da resistência cotidiana ao Golpe no interior das nossas salas de aula, em todos os níveis e modalidades de ensino, quanto documentavam a maneira como o Golpe de Estado potencializava golpes cotidianos nas relações profissionais, acadêmicas e interpessoais, de modo a banalizar tudo quanto reconhecemos como distante das nossas convicções democráticas.

Em ofício e em reuniões, a docente de Sociologia da Educação asseverou o rigoroso cumprimento da ementa do curso, atualizada por ela e fruto de diálogo com colegas de área, tendo sido aprovada em reunião de Departamento recente à investida realizada pelas Docentes pela Neutralidade. Foi relembrada e reforçada, por ofício e em reuniões, a informação de que as aulas de Sociologia da Educação eram lecionadas como consta a ementa aprovada, de modo a contemplar clássicos como Durkheim, Marx, Weber, Bourdieu, realizando debates que contemplam as categorias gênero, raça, geração, sempre ao lado da categoria classe.

Ao dizer de seu posicionamento favorável ao rodízio docente, desde que este fosse prática corrente em todas as disciplinas da Instituição, a docente de Sociologia da Educação se colocava como ocupando - após concurso público de provas e títulos que venceu em primeiro lugar - vaga que é pública e não de seu uso privado. Por essa 
razão, tal prática de docência coletivizada de uma disciplina deve seguir critérios fundamentados em avaliação realizada coletivamente e com transparência, podendo e devendo se dar em situações relacionadas ao diálogo com docentes da área de Fundamentos da Educação. Lia-se, no ofício, que se tornou também fonte de pesquisa, que, no entender da docente de Sociologia da Educação, jamais haveria de ser utilizado o rodízio para retirar docente de sala de aula em razão de receios docentes motivados por elementos que não estão transparentes no processo institucional de tomada de decisões e que ainda podem corresponder aos anseios de grupos autoritários, como o Movimento Brasil Livre (MBL), que busca proibir o trabalho com gênero na escola.

A docente de Sociologia da Educação, desse modo, se contrapunha ao rodízio de docentes correspondente à sua retirada de sala de aula por essa prática se assemelhar ao modo de argumentar e agir dos "movimentos" Escola Sem Partido e outros que nomeiam como "ideologia de gênero" a abordagem levada a termo pela docente nas aulas de Sociologia da Educação. Esta foi enfática ao afirmar que, antes de se questionar se era preciso rodízio e antes de se realizar avaliação de todos os docentes, a ser construída, aplicada, tabulada e analisada coletivamente, haveria de se avaliar o procedimento adotado pelas Docentes Pela Neutralidade. Estas pareciam não ter pensado duas vezes em excluir uma colega de suas funções laborais, garantidas como responsabilidades e direitos de seu cargo, em trabalho para o qual a docente teria legitimada formação, produção e para o qual ingressou em disputa pública de provas e títulos.

As Docentes Pela Neutralidade, que enviaram o recado e a consulta pelo Pombo Correio, pareciam ter assumido, nesse episódio, protagonismo fora de esquadro e sem localização adequada, o que só se evidenciou após a docente de Sociologia da Educação divulgar e debater ofício sobre o triste episódio. Uma vez chamadas para dialogar com a docente de Sociologia da Educação e, depois, com a Direção da Unidade e Coordenação de Curso, por um lado, as Docentes Pela Neutralidade assumiram ter acolhido e atuado a partir de reclamações de alunas isoladas que poderiam ser infundadas, com caráter difamatório e deslegitimador de toda uma prática profissional. Assim, as afirmações das Docentes Pela Neutralidade prescindiam de provas simples ou mesmo robustas, e ainda pareciam originarem-se de crenças pessoais das próprias docentes. Por outro lado, uma das Docentes Pela Neutralidade não assumiu seu posicionamento equivocado e, ainda afirmou, sentir-se magoada com a situação (por ela causada), sendo essa sua postura oficial relatada em ofício de resposta, enviado pela Direção de Unidade, documento este disponibilizado para a pesquisa em tela. 
Cabe destacar que, após procedimento administrativo de apuração dos fatos, motivado pelo ofício entregue pela docente de Sociologia de Educação, o Diretor de Unidade assegurou à ela, em reunião e em ofício, que havia um "mal entendido" e que o rodízio, diferente do que havia sido reportado pelo Pombo Correio, não era algo específico destinado à Sociologia da Educação. Vale destacar que essa hipótese sobre todo o episódio ter sido um "mal entendido" não foi algo que convenceu a docente ou as pesquisadoras que estudam o percurso inacabado e tortuoso de gênero nos cursos de Pedagogia. O que reportou o docente denominado Pombo Correio, sendo este um aliado da docente de Sociologia de Educação, não parecia ser um simples erro de comunicação. O fato de as Docentes Pela Neutralidade terem sido advertidas, em reunião, sobre a inadequação de suas posturas e atuações no episódio narrado pelo mesmo Diretor de Unidade que alega "mal entendido" expressa o cunho antidemocrático da ação destas docentes.

Apesar dessa aparente tentativa de conciliação advinda do Diretor de Unidade, diante dos acontecimentos, nos atuais tempos e na conjuntura nacional, a docente de Sociologia da Educação narrou que se sentiu desrespeitada, ao protagonizar o episódio em questão, o número de docentes que, pelo Brasil, ao lado de professoras pesquisadoras como Marlene de Fáveri, da Universidade do Estado de Santa Catarina, são acusadas - podendo até ser processadas - por serem quem são: mulheres, feministas e estudiosas de gênero, geralmente alocadas também no campo da esquerda. Há de se reforçar que o uso dos grifos aqui cumpre o papel de destacar que jamais essas mulheres serão - seremos - apagadas, caladas e, graças a textos como este, mais dificilmente, terão sua produção acadêmica deslegitimada pela pecha misógina de "muito militantes e, portanto, com produção acadêmica de duvidosa qualidade".

Nessa perspectiva, importa destacar que a docente de Sociologia da Educação ponderou que, ainda que se tivesse havido reclamação discente, esta haveria de ter sido encaminhada no âmbito dos trâmites usuais das avaliações institucionais docentes. A despeito de não agradar a toda gente, sempre é preciso garantir o pluralismo de ideias e abordagens na formação dos cursos de Pedagogia e Licenciaturas. As inseguranças e desconfortos como os apresentados pelas Docentes Pela Neutralidade, eventualmente expostos por alunas com ideário sectário ou religioso e fundamentalista, não devem ser motivo para argumentar não cumprimento de ementa, para propor retirada de docente de sala de aula, com rodízio ou outras práticas, sem sequer haver quantidade e qualidade de docentes para tal. 
Tendo feito essas ponderações no diálogo com seus pares, via ofício e também verbalmente, a docente de Sociologia da Educação recebeu pedido de desculpas de uma das Docentes Pela Neutralidade e do Pombo Correio; apoio da Direção da Unidade, da Coordenação do Curso de Pedagogia, da Chefia de Departamento e de colegas professores, como o atuante mediador denominado Pombo Correio.

A partir de flagrante episódio de desrespeito, houve a oportunidade de a docente de Sociologia da Educação não apenas tornar o episódio relato de pesquisa formativa e potencialmente fortalecedora, mas também colocar-se, mais uma vez, com responsabilidade e consciência pelo seu trabalho, o que, segundo ela, parecia estar sofrendo resistências por um conjunto de motivos. Dos dizeres da docente de Sociologia da Educação, coletados no ofício fornecido a nós por ela, destacamos trechos de singular expressão: “(...) Devo dizer que, depois de todas essas conversas, cresceu em mim a
impressão que há incômodo local pelo fato de ser uma mulher feminista,
lésbica, de outra cidade e ser docente lecionando em área curricular que
aparenta ser prestigiosa (Disciplina de Sociologia da Educação, da área de
Fundamentos da Educação). Pior que isso, trata-se ainda de docente lecionando
os clássicos e também a partir de categorias que hoje são vistas como
condenadas por uns e, na berlinda, por outros.”

“(...) Não é fácil ser percebida como estrangeira (pois não formada nesta Universidade e nem nascida nessa cidade), lésbica, feminista, assertiva e bem sucedida. Sou professora com postura crítica em campos (geográficos e temáticos) onde homens gays, brancos, cis eram, até minha chegada, o pensamento único sobre gênero e onde as mulheres heterossexuais que lidavam com a temática da pessoa com deficiência eram as reconhecidas lideranças sobre diferença e diversidade."

"Ser mulher é um ato político. Ser lésbica é um ato político. Ser do candomblé é um ato político. Ser feminista é um ato político. Ser professora de sociologia do modo como ensino é um ato político. Todos esses atos políticos me tornam quem sou e em constante defesa da democracia. Defender minha prática docente de ataques (locais ou nacionais, ingênuos ou não) é assegurar a democracia em variados níveis."

A docente de Sociologia da Educação conseguiu preservar o espaço de trabalho que vinha construindo na Instituição Federal que faz parte do estudo aqui parcialmente apresentado. Essa possibilidade de preservação, apesar das dificuldades e obstáculos que o episódio narrado representa, deu-se com o diálogo e com o apoio de colegas e da equipe de Direção Acadêmica da Unidade, mas, sobretudo, se deu pela importante rede de afeto e trabalho em conjunto com feministas lésbicas pesquisadoras e docentes de outras Universidades Federais, como nos relatou a docente de Sociologia da Educação. Na situação analisada, como em muitas outras Universidades, Unidades Acadêmicas e 
Cursos, faz-se notar o impacto do debate das relações de gênero e das abordagens feministas nos cursos de graduação. Considerar a categoria gênero, em perspectiva feminista, potencializa reflexões, práticas, ações e interações que descontinuam as tradicionais e conservadoras relações de poder. Estas estariam sendo ameaçadas em seus modos usuais e dominantes de se estabelecer, quando uma ou mais docentes de Sociologia da Educação estão em cena na instituição.

Desse modo, gênero, em perspectiva feminista, ao se colocar como ameaçador para determinados grupos e indivíduos, passa a ser alvo de ameaça. Feminismos e Gênero potencializam-se como ameaças simbólicas e reais para docentes e pesquisadoras, grupos e indivíduos que se se colocam em lugares privilegiados, com visões de mundo conservadoras. Parece ficar, então, mais fácil personificar a ameaça que a categoria ou o movimento social feminista representa na figura de quem o estuda, o considera em pesquisa ou dele se apropria organicamente, no pessoal que é político e no político que é pessoal.

Acompanhar essa situação tornou possível acessar o universo narrado e analisado pela docente de Sociologia da Educação. Representou uma vivência expressiva do quanto gênero e feminismo estão no caminho e são o caminho, mas, ainda, ambos inacabados. Como já foi dito e agora relembramos, a docente de Sociologia da Educação pode ser qualquer uma das pessoas que escreve ou que lê o presente artigo, cuja leitura - assim como a escrita - coloca a pensar como se somam A as usuais disputas do campo acadêmico, os debates da Escola sem Partido, da Lei da Mordaça e as grotescas acusações de "pregação de ideologia do gênero". Essa união perversa entre disputa acadêmica e variados discursos de setores que combatem a pluralidade de ideias se trata de uma união constitutiva de ambiente que pode atentar contra o lido democrático. A isso se soma a competição que já conhecemos, de outros tempos, em variados campos do sistema produtivo capitalista, mas, desta vez, com fantasiosa roupagem didática, pedagógica e acadêmica.

Cumpre relembrar, a bem da justiça histórica, que sempre houve quem defendesse o pensamento único, ora fazendo indevido uso da categoria classe como verniz para tentar disfarçar preconceitos, ora pregando intolerância religiosa diante de categorias como raça e gênero, somadas à categoria classe. Assim, expor ao debate a situação encontrada não se trata, exclusivamente, de analisar dados de pesquisa ou de reforçar corporativismos. Trata-se de defender a Universidade e a autonomia universitária, através da figura de servidora pública federal no exercício de sua função. 
Ao realizar tal defesa, serão prezados os princípios democráticos que devem reger não apenas a Universidade Pública, mas toda a vida em sociedade.

Para finalizar o presente trecho, cabe destacar que sua escrita se contextualiza na conjuntura do Golpe e das Eleições Presidenciais de 2018, quando a ministra Cármen Lúcia, do Supremo Tribunal Federal (STF), suspendeu, liminarmente, no dia 27 de outubro de 2018, atos judiciais e administrativos que determinavam os ingressos de policiais em universidades públicas e privadas pelo País. A ministra atendeu ação da Procuradoria-Geral da República (PGR), que pedia a garantia da liberdade de expressão e de reunião de estudantes e de professores nas instituições de ensino. As universidades lutavam, com aulas públicas, manifestações, panfletos e faixas, tanto contra o candidato identificado pelos seus eleitores e autoidentificado com o ideário fascista quanto em prol de campanhas pela democracia nas urnas e nas Eleições. A exemplo do que passou a docente de Sociologia da Educação, e, em outras proporções, grupos e indivíduos autoritários quiseram censurar os atos acadêmicos, a liberdade de expressão e tentaram impor o pensamento único e repleto de misoginia, racismo e lgbtfobia. Bem... o tiro parece ter saído pela culatra...

Por mais que o Golpe e o fascismo escancarado pelas Eleições Presidenciais 2018 tenham feito com que as Universidades Públicas fossem colocadas sob acirrado ataque, sobretudo sob a forma de tentativas de deslegitimação do funcionalismo público e demonização de conteúdos que se colocam no campo democrático, houve e sempre haverá resistência. Por mais que a categoria docente tenha dificuldade de vencer as lutas internas e reconhecer que são os setores ultraconservadores que lucram com as disputas, com as desigualdades e com a extinção da Educação Superior gratuita e pública, é, nesse nível de ensino, mantido e assegurado como garantia de educação e conhecimento de excelência para toda a sociedade, em que se preserva a democracia, sobretudo, em tempos de crise. A escrita do presente texto, que clama por democracia em cada linha, é a prova disso. E, como se não bastassem as reflexões até aqui tecidas, rememoramos situações do passado histórico, tanto recente quanto mais distante, narradas em filmes e em relatos de jornal, que serão objeto a seguir.

\section{O PASSADO COMO RESSIGNIFICAÇÃO DO PRESENTE COM ESPERANÇA DEMOCRÁTICA}


As reflexões oriundas da pesquisa que se descortinou nos acontecimentos em tela trazem à memória o filme Una giornata particolare, de Ettore Scola, filmado em 1977. Com título traduzido para o português como Um dia muito especial, essa película foi forte lembrança diante da narrativa da docente de Sociologia da Educação, feminista e estudiosa de gênero. O episódio que nos foi trazido pela experiência da professora nos deu parte da conta do percurso percorrido - e ainda a percorrer - dos modos como as relações de gênero são abordadas em cursos de Pedagogia da região Sudeste. Há um percurso repleto de obstáculos e, também, pleno de resistência, fortalecimento e possibilidades de debate e encaminhamentos democráticos diante de tensionamentos de retrocesso.

No artigo intitulado História como alegoria, Burke (1995, p. 197) aborda diferentes situações nas quais um evento histórico é citado para que uma circunstância atual, no presente, seja descrita, analisada, denunciada e, portanto, modificada. Trata-se de evocar um acontecimento geralmente passado quando, na verdade, o foco da inquietação reside em algo que nos preocupa no presente. No texto de Burke, há distinção entre alegoria pragmática e alegoria mística. A primeira seria relacionada a circunstâncias onde há restrições à liberdade de política. O segundo tipo de alegoria pressuporia um tipo de conexão não revelada entre dois acontecimentos (um passado e outro, presente).

O presente artigo, a partir dos atuais acontecimentos no cenário político pós Golpe à democracia, com o impeachment da Presidenta Dilma Rousseff e com o cenário fascista das Eleições 2018, assim como a partir de situações observadas em pesquisa, potencializa a recuperação de alguns acontecimentos históricos. Estes acontecimentos aparentemente não se relacionariam com o cenário educacional brasileiro Pós-Golpe e com acentuada mentalidade fascista, mas se prestam à análise de situações e inquietações atualmente vividas, debatidas, as quais precisam ser noticiadas. É importante expor e analisar o que se passa nos recônditos das Universidades, a fim de que se conheça a amplitude e profundidade das consequências e desdobramentos do "Golpe de Estado" e o fascismo que o sucedeu no tocante às influências desse cenário para as práticas acadêmicas e educativas, bem como para a produção de conhecimento.

Ainda que este artigo nos coloque a pensar, com especial destaque, a cena de cursos de Formação Docente ofertados em Universidades Públicas Federais, no Brasil, na região Sudeste, não há como não relacionar o que se passou com a docente de Sociologia da Educação com a morte do Reitor da Universidade Federal de Santa 
Catarina. Tentativas de aprisionamento e silenciamento são atentados contra ideias e contra pessoas que as representam em suas identidades. A docente foi, em um dia muito especial, dado o nefasto aniversário do Golpe, abordada em situação que foi por ela sentida como algo difamatório e a fez avaliar e rememorar toda a sua jornada de vida, carreira e escolhas, dada a sensação de invasiva violência. Em desproporcional medida de comparação, é possível estabelecer conjecturas sensíveis e solidárias acerca de como se sentiu o reitor Luis Carlos Cancellier de Olivo. Ele se suicidou no dia 02 de outubro de 2017, após ter sido preso em razão de acusações de ter obstruído, no entender de seus acusadores, investigações de má gestão, sem estar diretamente envolvido com o suposto desvio de milhões de reais. Ao fazer de sua morte um ato de protesto propositadamente ou não, após ter sido injustamente preso, despido e algemado, o acadêmico coloca nus não apenas o Golpe e o desmonte do Estado de Direito, mas despe a Academia do usual manto com o qual setores das Universidades insistem em se colocar como intocáveis analistas ou invisíveis magos.

Nesse sentido, parece haver um ethos acadêmico que faz grupos e indivíduos desenvolverem a crença que pessoas que devem manter um Currículo Lattes alimentado não são passíveis e necessitadas de serem defendidas pelos Direitos Humanos, da mesma maneira que devem ser protegidas as mulheres que sofrem violência doméstica ou a população negra que conhece o limite do racismo sob a forma do extermínio de sua juventude. E, aqui, ainda que de relance, relembramos que existem docentes negras e mulheres que, em um só tempo, sofrem racismo e podem sofrer violência doméstica, mas que devem, comme il faut, manter esses temas, quando muito, em suas pesquisas, desde que isso não as coloque naquilo que pode ser percebido como situação de imparcialidade ou discurso considerado panfletário. Afinal, não "fica bem" para uma pesquisadora se misturar ao seu tema de pesquisa, o que pode ser percebido como uma "confusa" aproximação entre ser sujeito da pesquisa que deveria apenas escrever e não vivenciar sob a forma de violência.

As reflexões repletas de sentimentos e memórias diante dessa sucessão de acontecimentos recuperam a lembrança de filmes como o que empresta seu nome ao presente artigo, o italiano Una giornata particolare dirigido por Ettore Scola em 1977 e outros tantos produzidos para retratar o fenômeno estadunidense denominado Macarthismo. Nesta passagem da história americana, o senador americano Joseph McCarthy promove caça a todos que percebe como comunistas e antiamericanos. Há numerosa e rica filmografia sobre esse momento, com a produção protagonizada, por 
exemplo, por Woddy Allen, nomeada America's Most Unlikely Hero, traduzido como Testa de Ferro por Acaso, dirigida por Martin Ritt, em 1976. Há, ainda, a filmagem da biografia Chaplin, dirigida por Richard Attenborough, de 1993, que mostra a expulsão do genial artista dos Estados Unidos por ser acusado de trazer propaganda comunista em seus filmes. Dentre os dois filmes americanos, vale notar que Martin Ritt, diretor de Testa de Ferro por Acaso, foi perseguido pelo Macarthismo, realizando, depois, tal obra como genial denúncia do fenômeno; e Chaplin se colocava como pacifista, não tendo, de fato, em sua obra, algo que pudesse ser colocado como motivo de expulsão do país que hoje se envergonha de ter tido esse capítulo em sua História.

No caso de Una giornata particolare, Ettore Scola pinça um dia tão especial quanto o 31 de agosto de 2016 para Dilma Rousseff e seu eleitorado ou, guardadas as proporções, quanto 31 de agosto de 2017, para a professora de Sociologia da Educação. Na Roma de maio de 1938, o encontro histórico de Benito Mussolini e Adolf Hitler ocorre para selar a união política que, no ano seguinte, levaria o mundo à $2^{\mathrm{a}}$ Guerra Mundial. Longe das paradas comemorativas, que, ao fundo da cena principal rufam seus tambores, assistimos ao encontro de Antonietta (Sophia Loren) e Gabriele (Marcello Mastroianni). Ela sendo uma solitária dona de casa e mãe de muitos filhos de um marido fascista. Ele, vizinho dessa orgulhosa família que dava braços e força ao fascismo, tinha sido demitido recentemente da rádio onde trabalhava, pelo fato de ser homossexual. Gabriele seria, nesse mesmo dia, buscado em casa por agentes do regime para ser preso, em razão de sua orientação sexual. A maior parte do filme se passa entre os dois apartamentos, onde habitam avizinhados Antonietta e Gabriele. Ele se coloca em busca de seu pássaro de estimação que foge e é encontrado pela infeliz mulher a quem, sem autonomia, resta o papel de parideira na manutenção do fascismo. Este, o mesmo regime que, nesse dia tão especial, ocasiona o encontro dos vizinhos para logo depois os separar, com a alusão à prisão de Gabrielle, pelo fato de ser gay, e com a manutenção do que pode ser visto como um tipo de prisão doméstica de Antonietta, pelo fato de ser mulher. Não é à toa que ambos perseguem um pássaro fujão. Seria ele o símbolo da liberdade de ambos, de um Estado, de uma Nação e do Mundo, que mudaria, ainda mais, e não necessariamente para melhor, depois da Segunda Guerra Mundial?

A retirada da Sociologia como disciplina obrigatória do Ensino Médio, na Educação Básica; o policiamento da disciplina de Sociologia da Educação, como relatado em pesquisa; o ideário dos grupos que falam por uma Escola sem Partido e 
defendem uma Lei da Mordaça. Todos esses fenômenos podem ser vistos como reedições dos movimentos descritos de modo fílmico por Ettore Scola e analisados na história estadunidense contada quando se focaliza o Macarthismo, em filmes exemplares como Chaplin e Testa de Ferro por Acaso.

Não é possível que vivamos e revivamos tudo isso e que as alegorias que se lançam sobre nós, como repetições históricas e ou como neuroses coletivas de controle fascista, não nos sirvam para ressignificar o presente e ter a certeza de que não são em vão os passos dados como atos de resistência, seja nossa, seja de Dilma Rousseff, seja de Ettore Scola, seja de Chaplin, seja da docente de Sociologia da Educação. Em diferentes tempos e espaços, os sujeitos citados seguem em movimento. Cada uma dessas pessoas-personagens citadas são representativas por demonstrarem, diferentemente, forte resistência na direção da preservação da democracia - único bem que deve ser, de fato, caro a cada pessoa individualmente, assim como a todas as pessoas e instituições coletivamente.

As mulheres pensadoras judias Hannah Arendt e Agnes Heller, perseguidas e, como tal, intelectuais de sua condição, de seu e de nosso tempo, nos avisam de um perigo. Elas nos alertam que as pessoas comuns podem acabar vendo o mal como algo normal, como algo a ser realizado como que por dever. Imaginamos que assim, como que por dever, devem ter se guiado em suas ações e em suas autoargumentações, tanto as Docentes Pela Neutralidade quanto os italianos que contaram ao fascismo sobre a homossexualidade de Gabrielle, em delação que o levou ao desemprego e ao cárcere. Nessa utilização da História como alegoria, por intermédio de recursos fílmicos, encontramos a obediência cega ao ideário tirano que, sem medir consequências, pode expulsar gênios do cinema de um país que se deseja referência na Sétima Arte; pode retirar docentes de saber comprovado das salas de aula, para as quais seus concursos e produções acadêmicas os/as destinaram; ou, no limite da violência fascista, pode encarcerar e matar Reitores.

Mais do que uma imitação da realidade, o cinema apresenta, dentre muitas possibilidades, efeito próximo ao que exerce a participação nos movimentos sociais, quando propicia o encontro com nossos pares. Com diferentes abrangências e específicas metodologias, o Cinema e os Movimentos Sociais são maneiras de não nos sentirmos sós, diante das dores e mazelas que aparentemente nos afligem como indivíduos mas que são enfrentadas e superadas como grupos e coletividades, formadas tanto nas ruas, em manifestações em prol da democracia, quanto nas 
salas de exibição, lugar do sonho (e aqui se utiliza, novamente, o texto sublinhado por motivação afetiva, durante escrita de trecho e texto especialmente pensado como estratégia de resistência).

Próximo não apenas do dinamismos dos movimentos sociais, o cinema pode ser colocado assemelhado aos sonhos:

\begin{abstract}
"Curiosa é a semelhança entre o mecanismo do sonho e as características de uma sala de projeção, denominada "situação cinema" por Mauerhofer. Em 1947, o Instituto de Filmologia de Paris dedicou um estudo sobre o estado de subjetividade do espectador na sala de projeção: o mundo exterior está ausente, o espectador se encontra num estado semelhante ao torpor, entregue à regressão e ao abandono, com a atenção totalmente concentrada a olhar a tela, num completo envolvimento emocional (bem diferente de ler um livro, escutar uma música ou assistir televisão). Qualquer ruído ou visão fora da tela remete o espectador à existência de uma realidade externa que o desperta para a presença do cotidiano, comprometendo o estado psicológico necessário para a perfeita adesão ao mundo do filme. O espectador na verdade não "assiste" ao filme, ele o vivencia de uma maneira, tão próxima do sonho e numa total intensidade, que não raro ele próprio se surpreende gritando, xingando, torcendo ou transpirando de emoção. O espectador desprende-se da poltrona, entra na tela e desfruta a vida emprestada pelo personagem, converte-se em protagonista do jogo simulado de eventos. O estado de relaxamento em que se encontrava foi favorecedor da atrapalhação mental, tornando difícil efetuar a "prova de realidade" que, segundo Freud, caracteriza o trabalho do sonho. A essa vivência convencionou-se chamar "impressão de realidade". (FERNANDES, 2005, p.70)
\end{abstract}

O presente texto, propositadamente, coloca em diálogo, em sua escrita, os sonhos, as situações coletadas em pesquisa, a abordagem alegórica de acontecimentos históricos, de produções cinematográficas e o ideário de Hannah Arendt e Agnes Heller sobre a banalidade do mal e o esquecimento do bem. Fazer esse rico feixe de referências pode fundar estratégia que nos encaminha para responder a uma pergunta, ao findar da pesquisa em desenvolvimento, a qual surgiu, juntamente, com sua resposta.

$O$ que acontece quando o percurso do Gênero está inacabado e nos deparamos com o Golpe e o Fascismo? Lutamos com todas as armas que temos, e a escrita, assim como a docência, sabe-se, são armas das mais potentes. Seguimos o caminho a ser percorrido e lidamos com os obstáculos como parte da paisagem, por mais desértica e dura que ela possa parecer. O percurso está inacabado, mas seguimos em nossa singular viagem rumo à democracia, com especial consideração das categorias raça, orientação sexual, classe, geração e gênero, em perspectiva feminista.

Nessa conjuntura, o ressurgimento de velhas ideologias de ódio sob novas formas de discriminação e com inéditas tecnologias faz ressuscitar, talvez, sob a forma de drone sobrevoando nossas salas de aula, a banalidade do mal, vestida de interdição 
ao debate de Gênero na Educação, seja por preconceito camuflado de medo de que os clássicos não estejam sendo apropriadamente ensinados, seja por apego a algo que se está chamando de coletividade e diversidade, mas não passa de desejo de tomar posse de solo acadêmico de Universidade Federal como mero latifúndio local. A despeito de onde se implanta uma Universidade Federal, sempre com respeito às especificidades regionais, ali é e sempre será lócus do encontro e da união indissociável das práticas educativas com os valores republicanos sobre os quais devem se assentar a educação para a democracia e o exercício da cidadania. Essa assertiva corresponde a um pilar da democracia brasileira e, queiram ou não os golpistas e os fascistas, o estamos sustentando em nossas aulas, pesquisas, ações nas comunidades e escritas como a do texto que aqui se encerra.

\section{REFERÊNCIAS:}

ARIAS, Julian. A banalidade do mal e o esquecimento do bem: O Brasil também continua de pé graças à maioria das pessoas, que sofre sem vender sua consciência. El País. Ediciones El País. Edição de 25 de agosto de 2017. Disponível em: https://brasil.elpais.com/brasil/2017/08/26/opinion/1503698941_685704.html.

Acessado em 06 de outubro de 2017.

BURKE, Peter. História como alegoria. Estudos Avançados. São Paulo: vol.9, n.25, 1995.

CASTRO, Mary Garcia. ALQUIMIA DE CATEGORIAS SOCIAIS NA PRODUÇÃO DOS SUJEITOS POLÍTICOS. Estudos Feministas, UFSC, Florianópolis: 1992.

CAVALLEIRO, Eliane dos Santos. Do silêncio do lar ao silêncio escolar: racismo e preconceito e discriminação na educação infantil. 2 ed., São Paulo: Contexto, 2003.

CRENSHAW, Kimberlé W. Documento para o encontro de especialistas em aspectos da discriminação racial relativos ao gênero. Estudos Feministas, UFSC, Florianópolis: 2002.

FERNANDES, Ana Lúcia Sampaio. Cinema e Psicanálise. Estudos de Psicanálise. Belo Horizonte, n. 28, 2005.

FRASER, Nancy. Da redistribuição ao reconhecimento? Dilemas na justiça numa era "pós socialista". Cadernos de Campo, n. 14/15, São Paulo: 2006.

FONSECA, Claudia. Quando cada caso NÃO é um caso: pesquisa etnográfica e educação. Revista Brasileira de Educação. Rio de Janeiro, ANPEd, n. 10, 1999.

LOURO, Guacira Lopes. Gênero, Sexualidade e Educação: uma perspectiva pósestruturalista. 14. ed. Petrópolis: Vozes, 2012. 
MARTINES, Felipe. Suicídio de reitor da UFSC mostra face da cruzada cega "contra a corrupção". Boletim de Notícias Consultor Jurídico. Edição de 02 de outubro de 2017. Disponível em: http://www.conjur.com.br/2017-out-02/morte-reitor-ufsc-mostraface-cruzada-corrupcao. Acessado em 06 de outubro de 2017.

MOLLO-BOUVIER, Suzanne. Transformação dos modos de socialização das crianças: uma abordagem sociológica. Educação e Sociedade. São Paulo: vol.26, n.91, 2005.

PUPO, Amanda. Cármen Lúcia suspende medidas que determinaram ações policiais em universidades. O Estado de S.Paulo. Edição de 27 de outubro de 2018. Disponível em: https://politica.estadao.com.br/noticias/geral,carmen-lucia-suspende-medidas-quedeterminaram-acoes-policiais-emuniversidades, 70002567633?fbclid=IwAR3PLR7vConv90uZCqG0zjqAr9opRJ7297PK Cb0WXFeqskjCjdQ2N4dgP90. Acessado em 27 de outubro de 2018.

TORRES, Aline. O suicídio do reitor para quem prisão foi ultraje e sentença de morte. El País. Ediciones El País. Edição de 04 de outubro de 2017. Disponível em: https://brasil.elpais.com/brasil/2017/10/04/politica/1507084756_989166.html.

Acessado em 06 de outubro de 2017. 